\title{
Endocytosis Inhibition
}

National Cancer Institute

\section{Source}

National Cancer Institute. Endocytosis Inhibition. NCI Thesaurus. Code C40805.

Endocytosis Inhibition involves interference with, or restraint of, cellular uptake of extracellular materials within membrane-limited vacuoles or microvesicles by invag ination of the plasma membrane. 